\title{
LA ÉTICA EN SITUACIONES DE CRISIS
}

\author{
CÉSAR FERnÁNDEZ ARCE*
}

\begin{abstract}
Resumen
El Perú, como muchos otros países, atraviesa una grave crisis de valores morales, pues estos han sido trastocados por otros de signo material, estimados en términos de utilidad, conveniencia o provecho personal; ni siquiera los derechos humanos prevalentes han sido un obstáculo para ello. Se hace imperativo, por ello, revalorar esos derechos, ya que constituyen exigencias indispensables de la dignidad humana. Se hace necesario, igualmente, tener en cuenta que el crecimiento económico es fundamental pero no basta; es menester, además, el crecimiento ético de las personas y el fortalecimiento de las instituciones en este ámbito, pues, de otro modo, no tendrá sentido afirmar que la persona humana es un fin en sí misma.
\end{abstract}

Palabras Clave: Crisis moral - Derechos humanos - Bienestar material Pobreza - Dignidad - Ética .

\begin{abstract}
Peru, as many other countries, goes through a crisis of moral values which have been disrupted by material ones estimated in terms of utility, convenience or personal benefit; not even those prevalent human rights have prevented such disruption. Thus, it is urgent to revalue those rights since they are an essential requirement for human dignity. Likewise, it is necessary to take into account that economic growth is vital but not sufficient. Besides, it is necessary to count with the people's ethical growth and the institutions' strengthening on this regard; otherwise, it will be senseless to state that a human being is an end for himself.
\end{abstract}

Key words: Moral crisis - Human rights - Material well-being - Poverty Dignity - Ethics

\section{Sumario}

1. Cuestiones generales. 2. Fundamentación de la ética. 3. Distribución de la riqueza en el mundo. 4. Una ética para tiempos difíciles.

\section{CUESTIONES GENERALES}

Después de cavilar un poco, consideré que el tema materia de este artículo debería ser de permanente actualidad y que moviese a hondas reflexiones por su especial trascendencia. Es así que finalmente decidí abordar el tema

\footnotetext{
* Ex Presidente del Poder Judicial y de la Corte Suprema de Justicia de la República de Perú.
} 
relacionado con la ética en tiempos de crisis, porque está relacionado con la razón y la fe, la búsqueda de la verdad, la libertad y del bien, y porque hay un renovado interés de la sociedad y del Estado por la persona humana y su desarrollo.

La ética no se alcanza con recetas sino formando conciencia a través de sólidos fundamentos con criterios morales en un medio donde los valores ya no son humanistas y la confusión sobre la naturaleza de los valores espirituales resulta preocupante.

Comencemos por el principio. ¿Qué es una crisis? Es una situación de cambio existencial para una persona o una institución. Puede ser bien una crisis de desarrollo o crisis de conocimiento, o por el contrario, puede tratarse de una crisis negativa que puede llevar a la destrucción de quienes la soportan.

Resulta indudable que el Perú, al igual que muchos países del mundo entero, vienen atravesando un período de crisis moral con ciertos indicadores que nos mueven a una honda reflexión y preocupación.

Estos indicadores múltiples y variados, son los siguientes:

a) Incremento de la violencia, de la corrupción, del narcotráfico y el chantaje. La violencia, es verdad, no es de ahora, ha sido de siempre. La violencia ha acompañado la historia. En el Perú, los años transcurridos desde el Tahuantinsuyo hasta ahora no han sido capaces de construir la paz que brota de la justicia. La injusticia es también una forma de violencia que lamentablemente es fuente de cultivo de más violencia. La injusticia tiene diversas formas de aparición, unas más sutiles que otras pero con un denominador común: terminan por generar más violencia y por destruir.

b) Existencia y proliferación del odio, la envidia y la venganza. Precisamente en el último número del semanario "Edu", editado por la Pontificia Universidad Católica del Perú, se informa sobre la publicación de una obra titulada: "El odio y el poder en el Perú", escrito por la doctora Claudia Rosas, profesora del Departamento de Humanidades de nuestra Universidad. Se destaca cómo a lo largo de nuestra historia ha sido una constante, lo cual como nosotros advertimos, constituye un factor que no contribuye a nuestra formación integral como persona humana ni al desarrollo del país, porque es más bien un factor de retraso como característica del hombre primitivo y que tiene en el fondo una característica digna de ser estudiada en el campo de la psicología. 
Muchas veces, la envidia se transforma en odio, el odio en venganza y violencia, que nunca conducen a la paz.

Para vencer los odios tenemos que reconocer que no somos un país con una identidad nacional (Moisés Lemlij: Profesor de Maestría en Estudios Teóricos en Psicoanálisis de la Universidad Católica).

Este autor afirma que el odio no es solo de los peruanos, sino un sentimiento básico y fundamental de nuestra especie en contraposición del amor, y que el odio no viene naturalmente sino que es una respuesta vinculada a la envidia cuando el hombre considera detestable que haya otros que tienen cosas que uno no tiene y si no llegamos a superarla se produce una frustración y con ella el odio y la destrucción del objeto envidiado o de la persona que lo posee.

La solución es la socialización que debe ser dada por el amor, la vida familiar y la sociedad. El egoísmo no sirve para el bien común.

c) Afectación de los núcleos sociales básicos de formación de las personas (familia, colegios, universidades, etc.)

d) Deterioro de la situación familiar en todas las urbes y particularmente en los barrios marginales donde se concentran el hambre y la miseria, el alcoholismo, la drogadicción y la promiscuidad y toda clase de corrupción de costumbres, aún cuando esos fenómenos no están ausentes en otros lugares del país.

e) Resquebrajamiento de los valores y costumbres tradicionales a cambio de la búsqueda del bienestar simplemente material y egoísta.

f) Grave estado de pobreza, mendicidad y abandono de la niñez.

Hay una crisis de valores que se extiende en todo el mundo. Se necesita volver a la ética. La ética humanista se alcanza formando conciencia a través de sólidos principios y criterios morales en un medio donde la ignorancia sobre los valores es grave, o cuando estos han sido trastocados por otros de signo material.

Actualmente percibimos ausencia de una correcta comprensión del significado de la libertad como atributo de la persona humana. Apenas la ha tenido para sectores restringidos de la comunidad. 
En el campo de la ciencia y de la tecnología, la humanidad ha alcanzado logros importantes, dando lugar a que la condición humana se haya visto beneficiada, pero con todos estos avances ¿ha encontrado la felicidad que todos aspiramos? La respuesta es negativa, la ha alejado, porque ha perdido la brújula que oriente su destino. El hombre parece ser que hubiera mutilado la imagen que antes se forjaba de sí mismo como imagen de Dios, dotado de razón y de libertad y con vocación de trascendencia.

Pero además, resulta oportuno señalar que tenemos la impresión de que en el hombre moderno existen ideales distintos a los ideales humanistas a los que desnaturalizan.

La felicidad a que el hombre aspira no se agota en el bienestar material que ahora se preconiza.

Las nociones de bien o mal, sobre las que se mueve el comportamiento humano, han sido reemplazadas por los conceptos de utilidad, conveniencia, provecho personal o la obtención de lo que queremos, aún incluso por la violencia. Si el fin perseguido en un caso concreto se logra violando derechos humanos prevalentes, Maquiavelo sigue entronizado con la máxima: "el fin justifica los medios".

¿Acaso innumerables guerras a la que los Estados han llevado a sus pueblos han tenido justificación? Muchas son las vidas humanas sacrificadas a cambio de obtener poder económico o político. Antes que a las personas, se destruye la verdad, por medio de la mentira para justificar las guerras. Hegel al ocuparse de este tema afirma que "la historia es el intento constante de justificar muchas cosas injustificables".

"El fin justifica los medios" sigue presente en el quehacer de la humanidad. No importa que con las guerras en muchas ocasiones se instrumentalice a la persona humana, se la destruya o se la esclavice. No importa que para fines de lucro o de poder o por venganza se pisotee a las personas.

El siglo XX, ha sido considerado como el más sangriento en la historia de la humanidad. Fue entronizado como una cultura de muerte, frente a una cultura de paz que los pueblos claman. La segunda guerra mundial costó la vida aproximadamente de 60 millones de personas.

Nos preguntamos si la Carta de las Naciones Unidas o Declaración de los Derechos Humanos vigente desde el 10 de diciembre de 1948, suscrita y 
ratificada por el Perú entre múltiples Estados del mundo, ha puesto fin al periodo de vergüenza, oprobio, miseria, corrupción y violencia vivida por la humanidad. Siguen las guerras, sigue la fabricación de armas mortíferas, la provocación para que los Estados continúen peleando y empobreciendo a los pueblos.

¿Acaso no es verdad que la libertad, la justicia, la paz y el desarrollo de los pueblos tienen por fundamento universal el reconocimiento de la dignidad de la persona humana y de los derechos iguales e inalienables de todos los miembros de la familia humana? La humanidad misma es una dignidad porque ninguno de sus miembros puede ser tratado como un instrumento sino siempre como un fin en sí mismo (Kant).

La ignorancia y el menosprecio de los derechos humanos siguen originando en el mundo, la barbarie y ultraje que violentan la conciencia de la humanidad.

¿Qué paradójico resulta comprobar el contraste entre los grandes avances humanos en los campos de la ciencia y de la tecnología y la violencia desatada en el mundo en todos los tiempos! El instinto bestial de destrucción propio del animal prevaleció sobre la razón, quedando la moral olvidada y, la dignidad del hombre, pisoteada.

Finalizada la segunda guerra mundial, muchos Estados soberanos, aprobaron y ratificaron múltiples tratados sobre derechos humanos. Su regulación nació, obviamente, de la necesidad impostergable de dar protección a la persona humana no solamente por parte del Estado a nivel individual sino a través de la Comunidad Internacional.

A partir del 10 de diciembre de 1948, fecha de la Declaración de los Derechos Humanos, la persona, independientemente de su origen, condición, raza o creencia, será titular de derechos subjetivos. Es un instrumento trascendental para la historia de la humanidad.

Afirma que la libertad, la justicia y la paz en el mundo, tienen por base el reconocimiento de la dignidad intrínseca y delos derechosiguales einalienables de todos los miembros de la familia humana. Que el desconocimiento y el menosprecio de los derechos humanos ha originado actos de barbarie y ultraje para la conciencia de la humanidad. Que la aspiración más elevada del hombre es el advenimiento de un mundo en que los seres humanos liberados del terror y de la miseria disfruten de la libertad de palabra y de creencias, resultando esencial que los derechos humanos sean protegidos por un régimen 
de derecho a fin de que el hombre no se vea compelido al supremo recurso de la rebelión contra la tiranía y la opresión.

Finalmente, declara la firme resolución de promover el progreso social y elevar el nivel de vida dentro de un concepto más amplio de libertad.

Esta hermosa e histórica declaración de principios se fundamenta en la dignidad de la persona humana, de la cual derivan sus principales derechos. El fundamento de esta categoría no es el hombre mismo, sino un ser supremo, absoluto y anterior a todo lo creado, capaz de infundir razón y libertad en la materia de la que estamos hechos. Se vive, sin embargo, una especie de "dictadura del relativismo", como afirma Benedicto XVI, porque prioriza esta corriente del postmodernismo, lamentablemente, que el ser humano no puede conocer con seguridad más allá del campo científico.

La declaración contenida en la aludida carta al reconocer la dignidad y respeto de todos los derechos fundamentales, es importante porque constituye base y sustento del ordenamiento jurídico, generando múltiples obligaciones para todos los Estados participantes, debiendo intervenir la comunidad internacional en caso de violaciones.

\section{FUNDAMENTACIÓN DE LA ÉTICA}

El origen y el fundamento de los derechos humanos nunca puede ser jurídico, sino previo a lo jurídico. Los derechos humanos pertenecen al mundo de la ética, no al mundo del derecho. El derecho positivo no crea los derechos humanos, su labor consiste en reconocerlos y convertirlos en normas jurídicas, dándoles plena efectividad y garantizándoles jurídicamente. La ética nos dice cómo debemos actuar. El poder político podrá acomodar o no su acción política a los postulados éticos.

Para la fundamentación ética, los derechos humanos aparecen como exigencias indispensables para una vida digna, son imperativos éticos que debemos trasladar convirtiéndolos en normas jurídicas.

Los valores que han de fundamentar los derechos humanos se derivan de la idea de dignidad humana y estos valores son la seguridad, la autonomía, la libertad y la igualdad.

Este año 2009 demuestra que, pese a las buenas intenciones, la violación de los derechos humanos no ha cesado, sobre todo en aquellos Estados denominados 
"del primer mundo", donde podría suponerse la existencia de una cultura de vida y civilización más avanzados.

Se creyó que la caída del muro de Berlín, durante la segunda mitad del siglo pasado, simbolizaría la victoria del humanismo sobre la instrumentalización inaceptable de la persona humana. Lamentablemente, poco tiempo después, hemos descubierto que la corrupción, la violencia, el terrorismo y el crecimiento del grado de pobreza aún continúan en gran escala.

\section{DISTRIBUCIÓN DE LA RIQUEZA EN EL MUNDO}

El World Institute for Development Economics Research (Wider) de la Universidad de las Naciones Unidas de Helsinski, ha publicado un nuevo estudio en el que por primera vez se investiga de manera detallada la distribución del ingreso de la riqueza y su evolución hasta el año 2000, tomando en cuenta el $94 \%$ de la población mundial. Dice en uno de sus acápites introductorios lo siguiente:

“Ya hace algo más de 250 años que la Academia de Gijón (1754) lanzó una pregunta y ofreció un premio para quien lograra responderla de manera adecuada: ¿Cuál es el origen de la desigualdad entre los hombres? ¿Es acaso la consecuencia de una ley natural? Rousseau se interesó por la cuestión y en respuesta escribió una obra sobre el origen de la desigualdad entre los hombres. Dijo, que la referida desigualdad social y política no es natural, no deriva de la voluntad divina, ni tampoco es consecuencia de una desigualdad natural. Por el contrario, su origen es el resultado de la propiedad privada, de la apropiación privada de la riqueza del mundo entero y de los beneficios privados derivados de esa apropiación.

Una cuestión central para las ciencias sociales es tratar de explicar el origen de la desigualdad social. Se señala también como causa la falta de libertad, íntimamente conectada con la desigualdad de una inmensa mayoría de personas en todo el mundo.

Actualmente, 1,200 millones de personas de todo el mundo viven con menos de un dólar por día, mientras que casi 850 millones de personas pasan hambre. La desigualdad mundial sigue aumentando y crece entre pobres y ricos en el interior de los países. La población mundial llega hoy a 6,500.000.000 habitantes.

El Instituto de Estadística e Informática INEI presentó con fecha 22 de mayo de 2009 las "Cifras de Pobreza en el Perú 2008". De acuerdo a esta medición, 
la pobreza disminuyó a 36.2\%, experimentando una reducción de 3.1\% con respecto al año anterior. Se consideran pobres a aquellas personas cuyo gasto per cápita, valorizado monetariamente, no supera el costo de la canasta alimentaria expresado como el umbral o línea de pobreza. El Perú actualmente tiene una población que llega a 28'220.764 habitantes.

Renán Quispe, Jefe del INEI, indicó que la mayor disminución de la pobreza se registró en el área rural que pasó de $64.6 \%$ en el año 2007 a $59.8 \%$ en el año 2008, es decir, $4.8 \%$ menos, mientras que en el área urbana se redujo en $2.2 \%$.

Mencionó que esas cifras de pobreza fueron elaboradas en el marco de un trabajo interinstitucional con organismos técnicos internacionales como el Banco Mundial (BM), Instituto de Investigación para el Desarrollo (IRD) de Francia, Fondo de Población de las Naciones Unidas (UNFPA), organismos gubernamentales nacionales como el Banco Central de Reserva, Ministerio de Economía y Finanzas, así como la comunidad académica y los centros de investigación del país.

La pobreza extrema en el año 2008 afectóal $12.6 \%$ dela población, disminuyendo en $1.2 \%$ con respecto al año 2007, precisándose que están consideradas en pobreza extrema aquellas personas cuyo gasto per cápita no cubre el costo de la canasta de alimentos.

En el área rural la pobreza extrema se redujo en 3.2\% y en $0.1 \%$ en el área urbana.

El derecho a la vida como derecho fundamental de la persona humana conlleva deberes para toda la sociedad. El derecho a la vida supone también la obligación de dar a los que no tienen medios de subsistencia lo necesario para asegurar su supervivencia, su vida. El derecho a la vida conlleva una solidaridad que se convierte no solo en deber moral sino en una obligación natural.

La pobreza no se limita solo a la escasez de bienes materiales sino también se da por la falta de acceso a los recursos esenciales que trasciende la penuria financiera y afecta la salud, la educación, la seguridad y las oportunidades de participación política de las personas.

Aunque el crecimiento económico es fundamental para sacar a las personas de la pobreza, ello no basta. Es menester el crecimiento ético de las personas y el fortalecimiento de las instituciones. 
La creciente desigualdad económica entre las distintas regiones del mundo y dentro de los mismos países es una causa decisiva de la violencia y del peligro de guerra civil. La injusticia es una forma de violencia.

Nos encontramos en la era de la globalización, pero una globalización sin solidaridad, sin humanismo, afecta negativamente a los sectores más pobres, han afirmado los obispos católicos reunidos en Aparecida, Brasil. Han dicho que no se trata simplemente de la explotación y opresión, sino de algo nuevo: la exclusión social. Con ello queda afectada en su misma raíz la pertenencia a la sociedad en que se vive, pues no se está abajo, en la periferia o sin poder, sino que se está afuera. Los excluidos no son solamente "explotados" sino “sobrantes" y desechables. (cfr. Documento Aparecida N 65, mayo 2007).

Jan Tinbergen, laureado con el Premio Nóbel de Economía en 1969, afirma que los problemas de la humanidad ya no pueden ser resueltos por los gobiernos nacionales. Lo que se necesita es un gobierno mundial. La corriente impulsa al mundo en este sentido.

Estamos, pues, frente al desafío de la pobreza y la miseria. Por tanto, resulta inevitable hablar del problema de las estructuras, sobre todo, de las que crean injusticias. El Papa Benedicto XVI, en el discurso inaugural del mismo encuentro de Aparecida ha afirmado enfáticamente que:

"Las estructuras justas deben brotar de un consenso moral de la sociedad sobre los valores fundamentales y sobre la necesidad de vivir estos valores con las necesarias renuncias, inclusive contra el interés personal".

La globalización solo cobra sentido cuando está al servicio de la persona humana. La persona humana es un fin en sí misma. El artículo $1^{\circ}$ de nuestra Constitución Política expresa que la defensa de la persona humana y el respeto de su dignidad son el fin supremo de la sociedad y del Estado.

La dignidad del hombre es intangible, corresponde al poder público y a la sociedad respetarla y protegerla.

La inviolabilidad y la inalienabilidad de los derechos del hombre son el fundamento de toda comunidad humana, así como de la paz y de la justicia en el mundo.

La proclamación de la dignidad intrínseca de todo ser humano en la Carta de las Naciones Unidas y en la Declaración Universal de Derechos Humanos es 
principio constitucional contemporáneo de orden internacional, que se debe traducir en una obligación erga omnes del respeto de todos esos derechos.

En el libro "Primero la gente", escrito por el Nóbel de Economía Amartya Sen, nacido en la India y el economista argentino Bernarde Kliksberg ambos académicos y humanistas, cuestionan desde la ética del desarrollo, la falta de equidad en la distribución de la riqueza planetaria. Afirman que si la ética y la economía se articularan, podrían surgir alternativas de solución en el mejoramiento de la vida de tantas personas que hoy día sufren. Hay pues una tarea ética que cumplir y que corresponde a todos: humanizar el mundo.

La globalización con todos los indudables logros positivos alcanzados, no avanza plenamente por el camino de la humanización como fuera de esperar, porque no se conoce adecuadamente el verdadero valor de los sufrimientos de la pobreza. Falta más justicia, más solidaridad y más compasión. La ambición desmedida de riqueza, o de poder, cualquiera fuere su naturaleza, llevan a la corrupción.

\section{UNA ÉTICA PARA TIEMPOS DIFÍCILES}

El sacerdote jesuita Ricardo Antoncich en el libro "Una ética para tiempos difíciles", Centro de Espiritualidad Ignaciana, reflexiona precisamente sobre la urgente necesidad por parte de la sociedad de actualizar los valores éticos que se vienen perdiendo y cómo se siente cada vez más la urgencia de volver a recuperarlos porque existe la sensación de que se van abandonando en la vida de los hombres. El dirá: "Nos acordamos del aire que respiramos cuando el ambiente se torna irrespirable".

La realidad de nuestro medio, punto de partida para el inicio del proceso de conocimiento, nos descubre precisamente un ambiente enrarecido por el fenómeno de la corrupción en todas sus formas, abiertas o solapadas, que corroe y destruye al hombre, a la familia y a la sociedad, trayendo como resultado el malestar que el mundo soporta.

No sería correcto afirmar que el problema es de hoy. Quizás ahora lo percibimos con mayor claridad, pero siempre ha existido, aunque ahora es más fácil descubrirlo por los avances de la ciencia, la tecnología y los medios de comunicación y difusión.

Esta percepción nos lleva a descubrir la necesidad antropológica de una toma de conciencia moral, y asimismo, una sincera disposición para asumir respon- 
sablemente el rol que nos corresponde vivir como personas humanas que buscan su realización plena en la felicidad como legítima aspiración humana.

Santo Tomás de Aquino, entre muchísimos teólogos importantes, señala puntualmente que el fundamento de la moral descansa en la propia naturaleza humana. Como dice Lorda en su obra "El arte de vivir" (Lorda Irraña, Juan Luis, "Moral, el arte de vivir", Madrid, España, 1994), la moral consiste en el arte de vivir dignamente como persona humana. Es el arte de saber usar bien la libertad con que ha sido creado el hombre por Dios. Es un arte que cada quien necesita aprender para vivir dignamente en la búsqueda del propio destino, que es alcanzar la felicidad plena. La libertad, sin embargo, no es un valor absoluto, sino más bien, un medio al servicio del hombre en el camino de su perfección. Está en función del bien como valor.

En la moral influyen dos valores muy importantes: el bien y la verdad. Por eso Platón llegó a afirmar que "no es posible conocer la conducta a seguir que haga bueno al hombre si desconocemos la verdad".

La bondad busca el bien de uno y del otro, es un valor ético, y esta es la cualidad inherente a determinados comportamientos auténticamente humanos que responden al sentido más profundo dado a la existencia y dignidad humana, nos dirá Lorda en su obra ya citada.

La moral no esclaviza, antes bien, hace libres a los hombres, porque enseña a hacer buen uso de la libertad mediante la adquisición de conocimientos necesarios y de costumbres y hábitos que permitan vivir dignamente.

La verdad es la luz de la inteligencia que permite distinguir el bien del mal. La verdad es el único camino que conduce a la libertad. La verdad nos hará libres. Lorda dirá que la ignorancia, el error y la debilidad de carácter, son los tres obstáculos de la libertad. Los dos primeros apagan la voz de la conciencia y la tercera hace al hombre incapaz de seguirla. El criterio de verdad no se determina por la opinión mayoritaria sobre algo determinado.

La persona tiene, además, libertad para elegir entre alternativas diferentes, aquella que es buena para nuestra naturaleza como persona humana. Esta traduce la esencia de nuestro ser.

La conciencia se forma con la educación pero sus raíces son innatas a cada cual. La conciencia no viene por reflexión racional, es la regla inmediata de moralidad, porque en ella reside la ley natural y, asimismo, la capacidad de poder discernir el propio comportamiento. 
La conciencia humana es libertad (Karl Jaspers). La conciencia es libre mas no infalible, por eso es necesaria una educación integral porque reduce la posibilidad de errar.

La formación humana en valores espirituales constituye uno de los fines esenciales de la educación.

Somos obra de nosotros mismos. El deber moral es una autoexigencia de la razón. Se alcanza el bien cuando se conoce y se respeta la verdad.

Para vivir moralmente, es menester además de desearlo, tener en claro en qué consiste vivir bien y después, adquirir libremente los hábitos para llevar a la práctica ese conocimiento. Kant en "Fundamentos de la metafísica de las costumbres" remite la dignidad de la persona a la autonomía de su voluntad y a la libertad. Dignidad y libertad van juntos.

Nuestra sociedad actual vive en crisis, bien porque desconoce la naturaleza e importancia de los valores morales en la vida, o porque prefiere vivir de espaldas a ellos. La alternativa es, entonces, vivir como persona humana con fe, razón y libertad o como animal guiado solo por el instinto.

El Padre Mac Gregor, sobre este tema nos ha dejado muy importantes reflexiones:

a) Cuando la educación de un país se desvincula del sustento cultural del que debe nutrirse, significa que se está construyendo un edificio sobre un lecho de arena.

b) La cultura de paz se orienta a conseguir que el imperativo moral de una persona lo lleve a la firme decisión de no usar la violencia para resolver un conflicto.

c) En el imperativo moral hay necesariamente un componente heterónomo, pero es imprescindible sobre todo, la decisión de no usar la violencia para resolver un conflicto. Es la moral autónoma, la que de hecho dirige a una persona en las opciones de vida. Toda la simbología de la paz tiene lugar tanto en la cultura objetiva como en la cultura subjetiva. La persona que ha aceptado el imperativo moral de no usar la violencia para resolver un conflicto, "posee una cultura de paz".

d) La economía no es solo producción de bienes y servicios convertidos en ganancia, es uso de las capacidades de la persona humana dignificándola y haciéndola constructora de un mundo mejor para todos.

e) Uno de los ideales más difíciles es alcanzar un régimen de producción de pleno empleo. Juan Pablo II ha llamado al trabajo: “La llave del arco de la construcción social". 